\title{
A impossibilidade no exercício da paternidade: algumas reflexões
}

The impossibility on paternity's role: some considerations

La imposibilidad en el ejercicio de la paternidad: algunas reflexiones

\author{
Sabrina Daiana Cúnico* \\ Dorian Mônica Arpini ${ }^{* *}$ \\ Juliana Cantele
}

\begin{abstract}
Resumo
A fim de conhecer quais as possíveis razóes que alguns pais têm para abdicar do exercício da paternidade ao final da relação conjugal, realizouse uma pesquisa qualitativa, da qual este artigo é um recorte. Integraram este estudo cinco pais que, anteriormente à pesquisa, participaram da mediação familiar em um núcleo de assistência judiciária e que, ao longo dos atendimentos com a Psicologia, demonstraram ter pouco ou nenhum contato com os filhos. A pesquisa foi realizada por meio da técnica de entrevistas semiestruturadas de questóes abertas, e os dados, analisados pela análise de conteúdo. Os relatos desses pais indicam que, embora todos eles tenham assumido a paternidade biológica, há certa dificuldade no estabelecimento de uma relação de proximidade com os filhos. Inferese, portanto, que esses pais não exercem, de fato, a paternidade e que isso se dê devido a uma impossibilidade em se posicionar afetivamente diante dessas crianças.
\end{abstract}

Palavras-chave: Relações familiares. Ausência paterna. Paternidade.

\begin{abstract}
In order to know what the possible reasons for some fathers renouncing parenthood when conjugal relationship ends are, a qualitative research was done from which this article was taken. In the preset one, five parents that, before the research, took part in family mediation in a legal system assistance core, and, throughout Psychological treatment, have shown to have little or no contact with their kids. The research was
\end{abstract}

\footnotetext{
Mestranda do Programa de Pós-graduação em Psicologia da Universidade Federal de Santa Maria (UFSM), psicóloga. Endereço: Rua Senador Cassiano, 746 - Bairro Dores. Santa Maria-RS. CEP: 97050-680. Telefone: (55) 8116-4950. E-mail: sabrinacunico@yahoo.com.br.

** Professora doutora do Departamento de Psicologia e do Programa de Pós-graduação em Psicologia da UFSM.

*** Mestranda do Programa de Pós-graduação em Psicologia da UFSM, psicóloga.
} 
developed through semi structured interview techniques consisting of opened questions and data was analyzed through content analysis. These fathers' responses indicate that, although all of them have assumed their biological parenthood, there is a barrier to establishing a close relationship with their children. It is implied, then, that these parents are unable to cope with parenthood and this happens due to an inability to take a stand on the fatherhood of those children.

Keywords: Family relations. Father absence. Fatherhood.

\section{Resumen}

A fin de conocer las posibles razones que algunos padres poseen para abdicar del ejercicio de la paternidad al final de la relación conyugal, se realizó una investigación cualitativa de la que este artículo es una parte. Integraron este estudio cinco padres que antes de esta investigación ya habían participado de una mediación familiar en un núcleo de asistencia judicial, y que a lo largo de los atendimientos con el equipo de Psicología, demostraron tener poco o ningún contacto con los hijos. La investigación fue realizada a través de la técnica de entrevistas semiestructuradas de cuestiones abiertas, y los datos analizados a través del análisis de contenido. Los relatos de los padres indican que, aun cuando todos ellos hayan asumido la paternidad biológica, existe una cierta dificultad a la hora de establecer una relación de proximidad con los hijos. Se infiere por lo tanto, que estos padres no ejercen, de hecho, la paternidad y que ello se debe a una imposibilidad de tomar una posición afectiva frente a esos niños.

Palabras clave: Relaciones familiares. Ausencia paterna. Paternidad.

\section{Introdução}

s separações conjugais que, até meados do século XX, eram ocasionais e traumáticas, tornaram-se, atualmente, quase que rotineiras (Corso \& Corso, 2011). Vale mencionar que uma dissolução matrimonial não pode ser considerada como resultado de apenas um único acontecimento, ainda que sempre exista um fator desencadeante. Ao contrário, ela resulta de uma série de conflitos já existentes e que acabam por culminar no afastamento do casal. Além disso, dificilmente as partes estarão emocionalmente em um mesmo estágio, o que pode desencadear a disputa e a exacerbação do conflito entre os ex-cônjuges (Pereira, 2011; Lima, 2008). 
Nesse contexto, o que se percebe, em muitos casos, é que os pais e mães em processo de dissolução matrimonial têm dificuldades para compreender que quem se separa é o casal conjugal, tendo o casal parental o dever de seguir cuidando, protegendo e provendo as necessidades materiais e afetivas da prole (Corso \& Corso, 2011; Féres-Carneiro, 1998; Pereira, 2011; Warpechowski \& Mosmann, 2012). Em outros termos, o casal não está liberado de seus deveres de parentalidade após um desentendimento, uma separação ou um divórcio (Dolto, 2011; Pereira, 2011).

O que se nota, contudo, é que, muitas vezes, os pais apresentam certa dificuldade em exercer a paternidade depois da dissolução matrimonial e atuam no sentido de anular a experiência familiar anterior, fundando uma nova família como se fosse a primeira (Corso \& Corso, 2011). Sendo assim, não raro, reduzem o convívio com os filhos provenientes da relação conjugal desfeita (Corso \& Corso, 2011; Furstenberg \& Nord, 1985), desligando-se afetivamente deles, já que estes passam a representar a lembrança de um passado que preferem esquecer (Corso \& Corso, 2011).

A maioria dos pais divorciados não tem a guarda dos filhos, ficando esta, quase que em sua totalidade, com as mães (Badinter, 1993; Brito, 2003; Dolto, 2011; Hurstel, 1999; Muzio, 1998). No entanto, sabe-se que somente uma minoria a reivindica no momento da separação. De acordo com essa perspectiva, é provável que o predomínio das guardas maternas não seja decorrente de uma decisão unilateral do juiz, mas sim de uma decisão unânime entre juiz, mãe e pai, pois enquanto este nem mesmo pensa em pedir a guarda para si, aquela nem imagina que a possa entregar a ele (Badinter, 1993; Padilha, 2008). Para Hurstel (1999, p. 130), "A ideia de que as crianças são 'das mães' é uma crença que homens e mulheres compartilham".

É nesse panorama que Ramires (1997) demarcará que a decisão de quem fica com os filhos após a separação conjugal ainda parece se configurar como uma escolha natural, o que acaba por favorecer aqueles homens que não têm o desejo de exercer de fato a paternidade. Nesse sentido, Dolto sustenta que, para alguns homens, é como se fosse normal "não assumir a educação de seus filhos caso deixassem a mulher 'legítima' com quem os tiveram” (Dolto, 2011, p. 43). Paralelamente a isso, ainda que algumas mulheres reclamem maior participação dos homens na educação dos filhos, muitas não aceitam bem o fato de o excompanheiro requerer a guarda compartilhada ${ }^{1}$ ou mesmo a guarda unilateral no momento da separação (Dorais, 1994), talvez por ainda se considerarem mais bem preparadas para assumir tal função.

\footnotetext{
Lei n. 11.698, de 13 de junho de 2008, que altera os arts. 1.583 e 1.584 da Lei n. 10.406, de 10 de janeiro de 2002 e determina "a responsabilização conjunta e o exercício de direitos e deveres do pai e da mãe que não vivam sob o mesmo teto, concernentes ao poder familiar dos filhos comuns instituindo responsabilidades".
} 
Efetivamente, o fato de, ainda hoje, a mulher ser considerada por muitos portadora de um instinto materno, o que a deixa mais apta que o pai para cuidar dos filhos, acaba contribuindo para que a paternidade seja representada socialmente como um papel secundário e menos prioritário para o desenvolvimento dos filhos (Badinter, 1985; Muzio, 1998; Reis, 2010). Essa propagação do mito do amor materno pode contribuir, de alguma maneira, com a desresponsabilização paterna diante dos cuidados e envolvimento com os filhos, o que é compartilhado e incentivado também pelas próprias mulheres e pela sociedade em geral (Badinter, 1985; Padilha, 2008; Staudt \& Wagner, 2008), que exaltam e criticam a boa e má mãe, enquanto que aceitam melhor as atitudes de pais que desempenham pobremente sua função (Muzio, 1998).

É nesse contexto que Pereira (2003) afirma que se vive hoje uma crise da paternidade, na qual os pais não assumem ou reconhecem para si o direito/ dever de participar ativamente da formação e desenvolvimento de seus filhos. O Direito faz a sua parte no que diz respeito ao abandono material, oferecendo mecanismos de cobrança e sanção aos pais que não pagam ou boicotam a pensão alimentícia. No entanto, o que realmente preocupa é o abandono psíquico e afetivo que a não presença do pai infringe à criança. Isso equivale a dizer que, por mais que as leis tentem, por meio de investigaçôes de paternidade e registros cartoriais, trazer garantias da paternidade, não há como assegurar que o genitor irá se comprometer em exercê-la. Ou seja, nem mesmo as condições jurídicas favoráveis garantem a eficácia do exercício da paternidade (Brito, 2003).

$\mathrm{Na}$ perspectiva de Silveira (1998), ainda povoa o imaginário social a ideia de que o exercício da paternidade emerge tão somente da existência de um genitor e uma criança, o que, segundo o autor, não acontece, já que os lugares de pai e filho são construídos com base nas relações interpessoais estabelecidas entre um e outro. É nesse sentido que se afirma que a verdadeira paternidade é sempre adotiva, ou seja, o pai que não "adota" o seu filho, ainda que biológico, jamais exercerá de fato a paternidade. Em outras palavras, nem todo o genitor conseguirá se constituir pai de seus filhos, visto que a paternidade é função exercida para além dos laços biológicos (Pereira, 2003; 2011; Silveira, 1998).

De modo geral, pode-se afirmar que a falta do envolvimento paterno na vida dos filhos tem potencial para gerar conflitos no desenvolvimento psicológico destes (Eizirik \& Bergmann, 2004; Sganzerla \& Levandowski, 2010), tanto diretamente, por seus efeitos em âmbito pessoal, quando indiretamente, pelas repercussões no ambiente familiar (Sganzerla \& Levandowski, 2010). 
Entende-se que a importância de um pai presente no ambiente familiar sirva tanto de referência acerca do universo masculino quanto seja alguém capaz de dar ressonância de forma positiva às questôes emocionais, sociais, afetivas e cognitivas dos filhos (Dantas, Jablonski \& Féres-Carneiro, 2004). Entretanto, vale lembrar que as repercussões da ausência do pai no ambiente familiar vão depender dos recursos emocionais desses filhos, do manejo dos membros da família e a presença de uma rede de apoio social, com o objetivo de minimizar os efeitos negativos dessa ausência (Sganzerla \& Levandowski, 2010).

Sob a luz dessa análise e a fim de aprofundar o conhecimento a respeito da paternidade e, mais especificamente, da ausência paterna, o objetivo deste estudo é apresentar um recorte da pesquisa intitulada "O (não) exercício da paternidade: algumas reflexões”, a qual teve por objetivo conhecer, por meio das falas dos pais, quais as possíveis razões que os levam a abdicar do exercício da paternidade ao final da relação conjugal.

\section{Método}

\section{Delineamento}

Trata-se de uma pesquisa de cunho qualitativo, a qual é definida, de acordo com Minayo (2012), como uma forma de trabalhar com o universo dos significados, dos motivos, das aspirações, das crenças, dos valores e das atitudes, ou seja, com um nível de realidade que não pode ou não deveria ser quantificado.

\section{Participantes}

Participaram do estudo cinco pais que, anteriormente à pesquisa, haviam buscado o serviço de mediação familiar em um núcleo de assistência judiciária gratuita $^{2}$ de uma instituição pública de ensino superior. Entre os participantes, encontram-se tanto pais que tinham filhos provenientes de apenas uma relação conjugal quanto pais de crianças de mais de um relacionamento amoroso. Nesses casos, a entrevista focou o relacionamento com o filho no qual o acordo realizado no Núcleo de Práticas Judiciárias se baseou. No quadro a seguir, apresentam-se informaçôes a respeito de cada participante.

\footnotetext{
A Psicologia está inserida no Núcleo desde 2005, por meio de um projeto de extensão desenvolvido em parceria. Inicialmente a proposta era que os estagiários de Psicologia ficassem à disposição do serviço para auxiliar nas situaçôes em que houvesse conflitos de família. Em 2007, o projeto ampliou as suas atividades, trabalhando além do plantão semanal com a proposta da mediação familiar.
} 
Quadro 1 - Caracterização dos participantes

\begin{tabular}{cccccc}
\hline Pai & Idade & Profissão & Filhos & Idade dos filhos & $\begin{array}{c}\text { Tempo de } \\
\text { separação }\end{array}$ \\
\hline P1 & 41 & Motorista & 1 & 9 anos & 9 anos e meio \\
\hline P2 & 21 & Desempregado & 2 & $\begin{array}{c}1 \text { ano e } 4 \text { meses (primeira } \\
\text { relação) }\end{array}$ & 3 anos \\
\hline P3 & 28 & Coletor & 4 & $\begin{array}{c}4 \text { meses (relação atual) } \\
11 \text { meses (relação atual) }\end{array}$ & 4 anos \\
\hline P4 & 33 & Motorista & 1 & 4 anos & 4 anos \\
\hline P5 & 22 & $\begin{array}{c}\text { Auxiliar de } \\
\text { limpeza }\end{array}$ & 1 & 2 anos & 1 ano \\
\hline
\end{tabular}

Fonte: dados da pesquisa.

* Filhos a quem a entrevista se referiu.

\section{Instrumentos}

Realizou-se com cada um dos participantes uma entrevista semiestruturada de questóes abertas, a qual é definida por Gaskell (2005) como sendo uma técnica que fornece os dados básicos para o desenvolvimento e a compreensão das relações entre os atores sociais e sua situação. Seu objetivo é "uma compreensão detalhada das crenças, atitudes, valores e motivações em relação aos comportamentos dos indivíduos em contextos sociais específicos" (Gaskell, 2005, p. 65).

\section{Procedimentos éticos e de coleta de dados}

Esta pesquisa foi aprovada pelo Comitê de Ética da Universidade pública de ensino superior a qual as pesquisadoras estão vinculadas, sob o número 23081.005766/2011-94. Após a aprovação pelo comitê, realizou-se o contato com o Núcleo de Assistência Judiciária, a fim de realizar a seleção dos participantes por meio de consulta às pastas dos usuários do serviço. Foram selecionados aqueles pais que eram ausentes da vida dos filhos, ou seja, pais que não mantinham nenhum contato ou mantinham contato irregular com a prole.

O contato inicial com estes pais se deu mediante ligação telefônica, na qual foi feito o convite para que participassem da pesquisa, sendo a entrevista agendada de acordo com a disponibilidade de cada um. Todos os sujeitos da pesquisa receberam, antes do início da entrevista, uma cópia do termo de 
consentimento livre e esclarecido, pelo qual ficaram cientes dos objetivos do estudo bem como do compromisso dos pesquisadores com o sigilo e a confidencialidade dos dados, assinando-o e autorizando a participação. Todas as entrevistas ocorreram no departamento de Psicologia da referida instituição de ensino.

\section{Análise de dados}

As cinco entrevistas realizadas foram gravadas e posteriormente transcritas na íntegra, e a análise dos dados foi obtida com base nessa transcrição. A análise foi qualitativa, utilizando-se a análise de conteúdo de Bardin (1979). Foram realizadas a leitura e a análise individual de cada entrevista transcrita, nas quais foram identificados os aspectos frequentes, por meio da carga afetiva contida na fala e, ou, pelas repetições de cada uma delas.

Depois, identificaram-se aspectos comuns entre as falas dos entrevistados e realizou-se o agrupamento desses temas em tópicos, a fim de promover uma melhor compreensão sobre os dados obtidos. Os resultados foram analisados sob a perspectiva de autores que discorrem sobre o tema e por meio de vinhetas ${ }^{3}$ retiradas das próprias entrevistas.

\section{Resultados e discussão}

Os resultados serão apresentados em duas categorias, quais sejam: entendimento sobre a paternidade, ao qual abrange questões advindas do julgamento que os participantes têm acerca do que é ser pai e quais as atribuições que estão implicadas no exercício da paternidade; e a impossibilidade no exercício da paternidade, que tem por objetivo trazer questôes relativas à impossibilidade que alguns pais têm em se posicionar afetivamente como pai de seus filhos, ou seja, não negam a paternidade biológica, mas não exercem a paternidade afetiva.

\section{Entendimento sobre a paternidade}

O relato dos pais neste estudo mostrou certa disparidade na forma como eles entendem e exercem a paternidade, o que pode ser observado nas falas a seguir:

\footnotetext{
As reticências entre parênteses se referem à retirada de partes repetidas ou não relevantes para o tema abordado e os colchetes indicam algumas explicaçôes da autora, a fim de clarificar o texto ao leitor. Optou-se por expor vinhetas extensas devido às falas dos pais terem sido extremamente representativas.
} 
Pra mim ser pai é uma pessoa que tá sempre junto, não ausente, que é o que eu to sendo, um pai não presente, e sim ausente... bastante. Não to seguindo os passos... dele, no dia a dia assim. (P4).

Esses dias, tava pensando nisso [...], que eu tenho que assumir que eu sou pai, por causa que é um negócio que eu fiz, não era esperado, mas eu tenho que tá sempre presente pra ele, que ele vai precisar bastante de mim... ser pai mesmo [...], tipo que nem eu fiquei um mês e meio longe dele, acho que eu não fui pai... porque nem uma vez por semana eu fui ver ele" [...] (P5).

Um dos entrevistados, mesmo relatando não ter uma relação de proximidade com um de seus quatro filhos, ao ser questionado sobre qual o seu entendimento sobre a paternidade respondeu:

Acho que... acho que pai é aquela pessoa que tem que tá... dando atenção 24 horas pro filho... dar amor, carinho... uma palavra amiga sempre que precisar. Não... falando em dinheiro, mas... falando em ajuda de outras maneiras, ou levar numa pracinha ou atender numa hora que se machuca ou se der um problema no colégio ou em casa, alguma doença... tá perto, tá junto, dá carinho, dá atenção, conversar na hora que der um problema (P3).

Interessante perceber que esse pai, ainda que tenha dificuldades no exercício da paternidade, tem uma compreensão ampliada a respeito das funções paternas, não vinculando a questão financeira como sendo o principal componente da paternidade. Diversos estudos vêm sendo realizados com o objetivo de constatar de que forma a paternidade vem sendo exercida pelos pais contemporâneos. Mesmo que muitos deles tenham constatado um pai mais participativo no ambiente familiar e que considera o afeto como sendo o principal componente da paternidade (Bottoli \& Arpini, 2011; Gomes $\&$ Resende, 2004; Silva \& Piccinini, 2007; Wagner, Predebon, Mosmann \& Verza, 2005), ainda persiste a crença de que a responsabilidade social do homem está na condição de provedor (Bustamante, 2005; Freitas, Silva, Coelho, Guedes, Lucena e Costa, 2009; Hurstel, 1999; Padilha, 2008; Ramires, 1997).

Outro participante, ao ser questionado sobre o seu entendimento a respeito do exercício da paternidade, respondeu: "Eu nem sei se eu tenho condiçôes de te responder por causa que... eu acho... pra mim, no meu ponto de vista, [...] eu só fui pai porque a única coisa que ela me exigiu foi a pensão" (P1).

Nesse contexto, não são raros os casos em que o genitor não guardião, 
geralmente o pai, acredita que somente o pagamento da pensão alimentícia qualifica o seu exercício da paternidade, o que acaba por sobrecarregar o outro genitor, que tem a função de cobrir a ausência daquele que não está exercendo o poder familiar (Grzybowski, 2002; Pereira, 2011). A respeito disso e levando em consideração o relato do participante acima, que afirma que sua ex-companheira não lhe exigiu nada além do pagamento da pensão alimentícia, questiona-se até que ponto as próprias mulheres não reforçam e perpetuam a ideia de que a função primordial do homem como pai é de prover materialmente a família, impedindo que tal concepção se modifique. $\mathrm{Na}$ perspectiva de Pereira (2011, p. 83) são ausentes o pai e a mãe que acreditam que somente o sustento material é o suficiente para a criação dos filhos.

Ao ser questionado sobre qual a frequência com que mantinha contato com seu filho, um dos pais relatou que, embora não convivesse frequentemente com a criança e não a visse já há bastante tempo, incomodava-lhe o fato de saber que o menino chamava de pai o atual companheiro da mãe. A fala seguinte ilustra essa questão:

Ai eu cobrei, dai, mas depois até... relevei porque ela me explico assim 'ah, ele mora com ele né, conhece ele como pai', tá concordo, até ai então... a gente não vai discutir, mas... cria ele ensinando quem é o pai e quem é que convive com ele, mas se ele pegar mais carinho por ele, eu não vou cobrar porque... eu tô ausente, né? (P3)

Diante desse relato, evidencia-se que o laço biológico, outrora tão fundamental para definição da paternidade, não garante mais a ligação permanente entre pais e filhos (Dorais, 1994; Pereira, 2011), uma vez que se entende que o exercício da paternidade é um ato diário de convívio, de cumplicidade e de amor, bem como de estabelecimento de regras e limites, vínculos que são invisíveis aos olhos da genética (Pereira, 2011).

Por outro lado, com as inúmeras mudanças advindas da separação conjugal, entre elas a multiplicação das famílias ditas recompostas, os homens passam a manter relações parentais com os filhos de outra parceira, com os quais não possuem nenhum laço biológico (Dorais, 1994; Warpechowski \& Mosmann, 2012), instaurando uma paternidade social, ou seja, uma paternidade na qual os vínculos construídos são respaldados, prioritariamente, por laços afetivos (Warpechowski \& Mosmann, 2012). No caso do participante acima, não tendo ele, o pai biológico, assumido a paternidade afetiva do seu filho, o companheiro da mãe parece se apresentar como um substituto para essa paternidade que se baseia na construção e estabelecimento de vínculos afetivos. 
É importante perceber que a experiência dos homens em relação à paternidade é sentida e vivida de modo muito particular, ou seja, não há um modelo paterno único. Assim, entende-se que a prática do exercício da paternidade é múltipla por ser cultural, circunstancial, temporal, específica e interpessoal, o que impede a definição de verdades a seu respeito (Silveira, 1998).

\section{A impossibilidade no exercício da paternidade}

Todos os participantes deste estudo são pais não detentores da guarda dos filhos e que mantêm pouco ou nenhum contato com a prole. Um participante, ao ser questionado sobre qual era o seu sentimento a respeito da sua ausência na vida do filho, respondeu:

Ah, é bem constrangedor pra mim. No meu ponto de vista, é por causa que... por mais que eu não me apegasse a ele do jeito que eu deveria me apegar... já por causa desse departamento que eu te falei [referindo-se a intromissão da ex-companheira], às vezes, eu sinto... uma mágoa, sei lá sabe? [...] Na realidade, eu não vi meu filho crescer, a melhor parte diz que é né? É da criança... Ter o contato desde novinho, desde pequeno né?... e poucos momentos eu tive com meu filho (P1).

É interessante perceber, analisando o recorte acima, que esse pai, de algum modo, ilustra a questão da impossibilidade da paternidade afetiva quando afirma "por mais que eu não me apegasse a ele do jeito que eu deveria me apegar", ou seja, esse pai parece reconhecer que o sentimento nutrido pelo filho não corresponde ao que ele próprio considera como sendo o ideal. Em outro ponto da entrevista, o mesmo participante relata um dos momentos que o filho lhe procurou para dizer que estava com saudades:

Até há uns mesinhos atrás, acho que uns cinco meses atrás, ele ligou lá pra casa chorando... é... que ele tava com saudade de mim e tudo [...] ai eu enrolei ele por causa que disse que o pai dele tava trabalhando muito, vamos dizer assim, não tinha quase tempo, mas é porque ele não entende ainda, se eu fosse falar pra ele que era por causa da mãe dele, ele não ia me entender porque acho que ele é muito novo ainda, eu penso assim. Eu queria deixar ele crescer um pouquinho mais, pra um dia eu pegar ele, nós sentar e eu... botar tudo a par do que que aconteceu (P1). 
Essa fala vai ao encontro dos dados de Dantas, Jablonski e Féres-Carneiro (2004), os quais afirmam que, de fato, alguns homens não conseguem apoiar os filhos no momento após a separação ou ainda apresentam dificuldades em manter relações com a ex-companheira, o que explica, em parte, o distanciamento destes em relação à prole. Além disso, raramente os pais que, pessoalmente, tem pouco ou nenhum contato com os filhos compensam essa ausência, comunicando-se com eles de outra forma, como por telefone ou e-mail, por exemplo (King \& Heard, 1999), aspecto que pôde ser identificado neste estudo por meio do recorte a seguir:

Até por telefone, até posso ligar qualquer hora, mas de eu ir lá, pegar e ficar com ele, ter alguns momentos com ele, algumas horas, ou final de semana é meio dificil [...] dai até isso [referindo a ligar para o filho] eu perdi a vontade porque... não adianta, tu falar com a pessoa por telefone é uma coisa, ainda mais sendo um filho teu, e agora... ter o contato é diferente. (P1)

Todos os participantes desta pesquisa têm um novo relacionamento amoroso, e alguns já têm filhos concebidos dessa nova relação. Pode-se pensar que o recasamento do pai pode afastá-lo ainda mais dos filhos provenientes da relação amorosa desfeita, visto que o pai pode acabar se envolvendo mais com o novo casamento e com os possíveis filhos dessa nova união (Grzybowski, 2007). Paralelo a isso, muitas vezes, para alguns pais, ausentar-se totalmente da vida dos filhos de relações anteriores é encarado como uma prova de amor e devoção para a atual companheira (Corso \& Corso, 2011).

Alguns participantes, no entanto, trouxeram realidades distintas da apresentada, o que reforça a concepção de que sua ausência na vida dos filhos é motivada por uma dificuldade em estabelecer um vínculo afetivo com essas crianças e não por um empecilho imposto pela atual companheira. As falas seguintes ilustram essa questão:

Ela [referindo-se à atual esposa] chega assim 'procura, eu não vou ficar com ciúmes', eu digo 'não, eu não quero procurar ele, não é o momento', ai ela diz assim 'aí, tu sabe, da minha parte, tu tá livre pra ir lá procurar ele, não precisa ir lá, marca um lugar... pra encontrar ele', eu digo 'quando eu tiver pronto, eu te falo' [...] (P4).

[...] até ela fala [referindo-se à atual esposa], porque que eu não vô vê, né, porque que eu não vô visitar [referindo-se ao filho da relação anterior]. Se um dia nós se separasse, se eu ia visitar ela... a D. [filha 
do atual casamento], coisa assim, ah mas... Ah, eu digo 'eu vô, fim de semana que vem eu vô, no outro eu vô', mas, acaba não indo... porque às vezes tu fica em casa, dá vontade de ficar em casa, às vez chove, aí dá vontade de ficar em casa descansando um pouco porque chega do serviço cansado né? [...] (P2)

Vale mencionar que a maioria dos pais entrevistados tem um acordo homologado judicialmente, do qual consta que a visitação pode ser exercida livremente, ou seja, o pai pode visitar os filhos sempre que assim o desejar. Contudo as visitas não acontecem regularmente, tendo sido a falta de tempo, o excesso de trabalho e as dificuldades com a ex-companheira os motivos alegados de forma mais frequente. As falas a seguir ilustram essa afirmação:

[...] porque é um negócio que é liberado pra mim vê ele e coisa, ai quando eu não vô, às vezes é por causa de mim mesmo, às vezes eu tenho meus compromissos também [...] (P5)

[...] porque quando nós tava namorando, eu vinha né [referindo-se à casa da ex-companheira], não reclamava... [risos] agora... não tem jeito [...] até daria pra vim todos os fim de semana e ficar um pouco ali, né, umas duas horas um pouco mais, só que, às vezes, tem outras coisas pra fazer e coisa assim [...] (P2)

É nesse contexto que Bruno (2003) afirma que nem sempre a livre visitação irá atender às necessidades fundamentais da criança de conviver com ambos os genitores. Isso porque, em muitos casos, não ter um esquema de visitação previsto em lei e não tendo os filhos consigo cotidianamente pode fazer com que o não guardião reorganize sua rotina, após a separação, não prevendo espaço para os filhos.

Um participante, que também tem um acordo homologado judicialmente estipulando a livre visitação, ao ser questionado sobre o que sente ao ver a foto do filho que nunca viu pessoalmente respondeu:

[...] Nada, nada mesmo ainda, sei que, mais pra frente, pode ser que mude, mas agora no momento... não tenho nem vontade de conhecer. (P4)

[...] Eu gosto das minhas sobrinhas, dos meus sobrinhos eu gosto, tudo, beih, pra mim vou, brinco com eles tudo isso ai, mas o C. assim, eu não tenho esse interesse de procurar pra brincar, fazer um carinho, nada. (P4) 
De acordo com esse pai, a sua principal recusa em conhecer o filho é decorrente da forma com que a mãe do menino contou sobre a gravidez, a qual, segundo ele refere, esperou mais de dois meses de gestação para comunicá-lo que seria pai. No entanto, pode-se pensar aqui que o real motivo em não aceitar o filho possa ser uma dificuldade sua em assumir as responsabilidades e deveres que a paternidade impóe. Infere-se isso devido a se entender que a justificativa apresentada por ele pareça frágil demais para ser sustentada por quatro anos.

Tal situação vai ao encontro do que postula Silveira (1998), quando afirma que nem todo o genitor conseguirá se constituir pai de seus filhos, visto que a paternidade é função exercida para além dos laços biológicos. Nessa perspectiva, a impossibilidade da paternidade se configura como uma dificuldade que alguns pais têm de estabelecerem um vínculo afetivo e ocuparem seu lugar na vida dos filhos, construindo e reconstruindo uma relação de afeto e proximidade que transcende o pagamento da pensão alimentícia e o registro no cartório civil. A fala seguinte é ilustrativa nessa questão:

[...] com o L. é diferente, o L., eu..., eu sei a falta que ele sente de mim né, tanto que eu sinto dele, mas eu não consigo procurar ele. Já os outros eu procuro [...] mas, eu não consigo ter esse mesmo amor que eu tenho com o... com o L. e que eu tenho pelos outros né? Não consigo ter e... não é por ele [...] Ele é como uma coisa que veio pra tentar me segurar, me agarrar [...] Eu já peguei esse sentimento de raiva já... eu não consegui, eu tentei me desprender muitas vezes e, às vezes, quando eu tô sozinho em casa, eu choro, eu sinto a falta dele, mas... logo em seguida, vem aquela... aquela raiva já, 'bah, por causa dele tá acontecendo tanta coisa', me prejudica em casa com minha esposa, me prejudica no serviço, porque dai começa, ou ligam do fórum ou me ligam da... da assistência social ou tem que tá depositando pensão, e é sempre no fim do mês é o mesmo assunto e isso tá me perseguindo, vai me perseguir a vida toda [...](P3)

Diante do exposto, entende-se que o estabelecimento do vínculo entre pai e filho não se dá instantaneamente no momento da gravidez e tão pouco se desfaz com a separação. Pelo contrário, trata-se de um processo complexo, no qual as características do vínculo tendem a se manter e provavelmente irão se expressar na forma com que os pais reorganizarão a vida e sua participação afetiva na vida dos filhos após a separação conjugal (Warpechowski \& Mosmann, 2012). 
Considerando tais aspectos e levando em conta que, com bastante frequência, é a criança que suscita no pai a função paterna, pode-se afirmar que é preciso de tempo para que um pai se torne pai, visto que é preciso que o filho o ame e solicite que esse amor seja retribuído. Quando essa relação é interrompida de forma prematura por uma separação conjugal, é possível que alguns pais não consigam, posteriormente, exercer de fato a paternidade (Dolto, 2011).

Salienta-se que todos os pais que participaram deste estudo relataram terem sido pais num momento em que o relacionamento conjugal já havia terminado ou estava em vias de dissolução. Assim, pouco conviveram com as crianças desde seu nascimento, o que pode explicar, em certa medida, o comportamento ausente e pouco afetivo que mantêm hoje com a prole. Nesse panorama, Silveira (1998) salienta que, assim como os pais adotam ou rejeitam os seus filhos, os filhos também poderão adotar ou rejeitar os seus pais, visto que a relação entre eles é coconstruída e reconstruída permanentemente. Dessa forma, as únicas pessoas que realmente poderão ensinar aos pais a exercerem adequadamente a sua paternidade serão seus próprios filhos.

\section{Considerações finais}

Este trabalho se propôs a apresentar alguns dos resultados de uma pesquisa que teve por objetivo conhecer, por meio das falas dos pais, quais as possíveis razóes que os motivam a abdicar do exercício da paternidade ao final da relação conjugal.

Todos os participantes, de alguma maneira, aceitaram a paternidade, já que realizaram o registro civil e deram seu nome às crianças, bem como vêm cumprindo com o pagamento do valor da pensão alimentícia estipulada por lei. No entanto, considerando o exercício da paternidade como o estabelecimento de uma relação construída pela constituição de vínculo afetivo entre pai e filho, pode-se dizer que os pais entrevistados não exercem de fato a paternidade. Assim, pode-se concluir que a paternidade não é um acontecimento simples e que se dá tão somente no nascimento de uma criança. Ao contrário, ser pai pressupóe uma vivência em que se busca evitar o distanciamento dos filhos, mesmo após uma separação conjugal.

Ressalta-se a importância de que esses pais, mesmo sabendo qual tema seria abordado, compareceram no dia da entrevista, dando sua contribuição e falando abertamente sobre as suas dificuldades em relação à paternidade. Com base nisso, pode-se pensar que há um reconhecimento por parte deles de que a situação vivida em relação à paternidade não é a ideal. Esse 
reconhecimento, aliado ao comparecimento no dia da entrevista, faz pensar que a dificuldade que esses homens estão tendo em se colocar afetivamente como pai de seus filhos não é uma situação definida e, ou, resolvida para eles. Tal aspecto permite pensar que a relação pai-filho, tão frágil nesse momento, poderia posteriormente ser alterada com vistas à construção de uma efetiva vivência de paternidade.

Tem-se a convicção de que este estudo não esgota a problemática da paternidade, em especial no que se refere à ausência paterna. No entanto, entende-se que ele pode contribuir para que algumas questôes sejam pensadas, principalmente no que tange ao desenvolvimento dos papéis parentais após uma dissolução conjugal.

\section{Referências}

Badinter, E. (1985). Um amor conquistado: o mito do amor materno. Rio de Janeiro: Nova Fronteira.

Badinter, E. (1993). XY: sobre a identidade masculina. Rio de Janeiro: Nova Fronteira.

Bardin, L. (1979). Análise de conteúdo. Lisboa: Ediçōes 70.

Bottoli, C. \& Arpini, D. M. (2011). O exercício da paternidade na separação conjugal. In F. P. Jaeger, C. S. Kruel \& A. C. Siqueira (Orgs.), Parentalidade e contemporaneidade: os desafios para a Psicologia. (pp. 123-150). Santa Maria: Centro Universitário Franciscano.

Brito, L. M. T. (2003). Igualdade e divisão de responsabilidades: pressupostos e consequências da guarda conjunta. In G. C. Groeninga \& R. C. Pereira (Orgs.). Direito de família e psicanálise: rumo a uma nova epistemologia (pp. 325-337). Rio de Janeiro: Imago.

Bruno, D. D. (2003). Direito de visita: direito de convivência. In G. C. Groeninga \& R. C. Pereira (Orgs.). Direito de família e psicanálise: rumo a uma nova epistemologia (pp. 311-324). Rio de Janeiro: Imago.

Bustamante, V. (2005). Ser pai no subúrbio ferroviário de Salvador: um estudo de caso com homens de camadas populares. Psicologia em Estudo, 10 (3), 393-402. 
Corso, D. L. \& Corso, M. (2011). A psicanálise na Terra do Nunca: ensaios sobre a fantasia. Porto Alegre: Penso.

Dantas, C., Jablonski, B. \& Féres-Carneiro, T. (2004). Paternidade: considerações sobre a relação pais-filhos após a separação conjugal. Paidéia, 14 (29), 347-357.

Dorais, M. (1994). O homem desamparado. São Paulo: Loyola.

Dolto, F. (2011). Quando os pais se separam. (2a ed.). Rio de Janeiro: Zahar. (Texto original publicado em 1989).

Eizirik, M. \& Bergmann, D. S. (2004). Ausência paterna e sua repercussão no desenvolvimento da criança e do adolescente: um relato de caso. Revista de Psiquiatria do Rio Grande do Sul, 26 (3), 330-336.

Féres-Carneiro, T. (1998). Casamento contemporâneo: o difícil convívio da individualidade com a conjugalidade. Psicologia: Reflexão e Crítica, 11 (2), 379-394.

Freitas, W. M. F., Silva, A. T. M. C., Coelho, E. A. C., Guedes, R. N., Lucena, K. D. T. \& Costa, A. P. T. (2009). Paternidade: responsabilidade social do homem no papel de provedor. Revista de Saúde Pública, 43 (1), 85-90.

Furstenberg, F. \& Nord, C. (1985). Parenting apart: patterns of childrearing after marital disruption. Journal of Marriage and the Family, 47 (4), 893-904.

Gaskell, G. (2005). Entrevistas individuais e grupais. In M. Bauer \& G. Gaskell (Orgs.). Pesquisa qualitativa com texto, imagem e som. (pp. 64-89). Petrópolis: Vozes.

Gomes, A. J. S. \& Resende, V. R. (2004). O pai presente: o desvelar da paternidade em uma família contemporânea. Psicologia: Teoria e Pesquisa, 20 (2), 119-125.

Grzybowski, L. S. (2002). Famílias monoparentais: mulheres divorciadas chefes de família. In A. Wagner (Org.). Família em cena: tramas, dramas e transformaçôes. (pp. 39-53). Petrópolis: Vozes.

Grzybowski, L. S. (2007). Parentalidade em tempo de mudanças: desvelando o envolvimento parental após o fim do casamento. Tese de Doutorado, Programa de Pós-graduação em Psicologia, Pontifícia Universidade Católica do Rio Grande do Sul, Faculdade de Psicologia, Porto Alegre. 
Hurstel, F. (1999). As novas fronteiras da paternidade. Campinas: Papirus.

King, V. \& Heard, H. (1999). Nonresident father visitation, parental conflict, and mother's satisfaction: What's best for child well being? Journal of Marriage and the Family, 61 (2), 385-396.

Lei n. 11.698. (2008, 13 de junho). Altera os arts. 15.83 e 1.584 da Lei n. 10.406, de 10 de janeiro de 2002 - Código Civil, para instituir e disciplinar a guarda compartilhada. Diário Oficial da União.

Lima, A. A. (2008). Psicologia jurídica: lugar de palavras ausentes. Aracaju: Evocati.

Minayo, M. C. S. (2012). O desafio da pesquisa social. In M. C. S. Minayo (Org.). Pesquisa social: teoria, método e criatividade (31 a ed., pp. 9-29). Petrópolis: Vozes.

Muzio, P. A. (1998). Paternidade (ser pai)... Para que serve? In P. Silveira (Org.). O exercício da paternidade (pp. 165-174). Porto Alegre: Artes Médicas.

Padilha, C. C. (2008). Quando o pai vira réu por alegação de abandono afetivo. In L. M. T. Brito (Org.). Famílias e separaçôes: perspectivas da Psicologia jurídica (pp. 187-217). Rio de Janeiro: ED/UERJ.

Pereira, R. C. (2003). Pai, por que me abandonaste? In G. C. Groeninga \& R. C. Pereira (Orgs.). Direito de família e psicanálise: rumo a uma nova epistemologia (pp. 219-228). Rio de Janeiro: Imago.

Pereira, R. C. (2011). Divórcio: teoria e prática. Rio de Janeiro: GZ.

Ramires, V. R. (1997). O exercício da paternidade hoje. Rio de Janeiro: Rosa dos Tempos.

Reis, E. F. (2010). Varas de familia: um encontro entre Psicologia e Direito. Curitiba: Juruá.

Resolução n. 016/2000. (2000, 20 de dezembro). Dispõe sobre a realização de pesquisa em Psicologia com seres humanos. Brasília: Conselho Federal de Psicologia.

Resolução n. 196. (1996, 10 de outubro). Diretrizes e normas regulamentadoras de pesquisas envolvendo seres humanos. Bioética, 4 (2), 15-25.

Sganzerla, I. M. \& Levandowski, D. C. (2010). Ausência paterna e suas repercussōes para o adolescente: análise da literatura. Psicologia em Revista, 16 (2), 295-309. 
Silva, M. R. \& Piccinini, C. A. (2007). Sentimentos sobre a paternidade e o envolvimento paterno: um estudo qualitativo. Estudos de Psicologia, 24 (4), 561-573.

Silveira, P. (1998). O exercício da paternidade. In P. Silveira. O exercício da paternidade (pp. 27-39). Porto Alegre: Artes Médicas.

Staudt, A. C. P. \& Wagner, A. (2008). Paternidade em tempos de mudança. Psicologia: Teoria e Prática, 10 (1), 174-185.

Wagner, A., Predebon, J., Mosmann, C. \& Verza, F. (2005). Compartilhar tarefas? Papéis e funções de pai e mãe na família contemporânea. Psicologia: Teoria e Pesquisa, 21 (2), 181-186.

Warpechowski, A. \& Mosmann, C. (2012). A experiência da paternidade frente à separação conjugal: sentimentos e percepções. Temas em Psicologia, 20 (1), 247-260. 